\title{
Meat quality, post-mortem proteolytic enzymes, and myosin heavy chain isoforms of different Thai native cattle muscles
}

\author{
Chanporn Chaosap ${ }^{1, *}$, Panneepa Sivapirunthep ${ }^{1}$, Ronachai Sitthigripong ${ }^{2}$, Piyada Tavitchasri ${ }^{3}$, \\ Sabaiporn Maduae ${ }^{2}$, Tipyaporn Kusee ${ }^{2}$, Jutarat Setakul ${ }^{2}$, and Kazeem Adeyemi ${ }^{4}$
}

\footnotetext{
* Corresponding Author: Chanporn Chaosap Tel: +66-83-882-9217, Fax: +66-2-326-4324 E-mail: chanporn.ch@kmitl.ac.th

${ }^{1}$ Department of Agricultural Education, Faculty of Industrial Education and Technology, King Mongkut's Institute of Technology Ladkrabang, Bangkok 10520, Thailand

2 Department of Animal Technology and Fishery, Faculty of Agricultural Technology, King Mongkut's Institute of Technology Ladkrabang, Bangkok 10520, Thailand

${ }^{3}$ Department of Animal Science, King Mongkut's Institute of Technology Ladkrabang, Prince of Chumphon Campus, Chumphon 86160, Thailand

${ }^{4}$ Department of Animal Production, Faculty of Agriculture, University of Ilorin, PMB 1515, Ilorin, Nigeria

ORCID

Chanporn Chaosap

https://orcid.org/0000-0002-3816-1884 Panneepa Sivapirunthep

https://orcid.org/0000-0002-7126-2732 Ronachai Sitthigripong

https://orcid.org/0000-0002-8671-0606 Piyada Tavitchasri

https://orcid.org/0000-0001-6753-3627 Sabaiporn Maduae

https://orcid.org/0000-0001-6209-774X Tipyaporn Kusee

https://orcid.org/0000-0001-6769-4973 Jutarat Setakul

https://orcid.org/0000-0002-8166-5367

Kazeem Adeyemi

https://orcid.org/0000-0002-6719-2081
}

Submitted Nov 24, 2020; Revised Mar 11, 2021; Accepted Apr 10, 2021
Objective: This study investigated the meat quality characteristics, endogenous proteolytic enzymes, collagen content, and myosin heavy chain (MyHC) isoforms of different muscles of Thai native cattle (TNC).

Methods: Infraspinatus (IF), Longissimus thoracis (LT), and Supraspinatus (SS) muscles were obtained from two TNC breeds, Kho-Lan $(\mathrm{KL}, \mathrm{n}=7)$ and Kho-Isaan $(\mathrm{KI}, \mathrm{n}=7)$. The muscle and meat characteristics of TNC breeds and their relationship with MyHC expression were examined.

Results: Three MyHC isoforms namely MyHC I, MyHC IIa, and MyHC IIx were detected in the muscles. The KL had higher $(\mathrm{p}<0.05)$ MyHC IIx than the KI. The IF muscle had higher $(\mathrm{p}<0.05) \mathrm{MyHC}$ I compared to other muscles. The LT muscle had the least MyHC I. The LT had higher $(\mathrm{p}<0.05)$ MyHC IIx than the IF and SS muscles. The IF presented the least MyHC IIx. The KL had higher $(\mathrm{p}<0.05)$ lightness and moisture content and lower crude protein, redness, cooking loss, shear force, and calpastatin than the KI. The glycogen, total collagen, soluble collagen, crude protein, ash contents, and troponin $\mathrm{T}$ degradation product of IF and SS were lower $(p<0.05)$ than that of LT. Ether extract in LT was lower $(p<0.05)$ than that of IF and SS. The percentage of MyHC I, MyHC IIa, and MyHC IIx were significantly correlated with muscle and meat characteristics of TNC.

Conclusion: These results suggest that the differences in the MyHC isoforms may partly account for the variation in meat quality between breeds and among muscles of TNC.

Keywords: Calpain; Calpastatin; Collagen; Glycogen; Troponin

\section{INTRODUCTION}

The beef cattle population in Thailand recently is about 5.40 million heads. Beef cattle in Thailand can be classified into three groups according to their genetic types, Thai native cattle (TNC)/crossbreds $56.60 \%$, purebreds/crossbreds $40.47 \%$, and fattened cattle $2.93 \%$ [1]. The TNC are one of the most economically important domestic animals in Thailand raised by smallholder farmers in mixed crop-livestock systems [1,2]. The TNC have characteristic of Bos indicus (Zebu), including the distinctive dorsal hump [1]. Despite being small and having a slow growth rate, TNC are well adapted to harsh and humid climates. Hence, they have high resistance to ticks, other parasites, and diseases [3]. They are capable of utilizing agricultural by-products or low quality ingredients such as feeds as well as having high fertility and good mothering ability [3]. There are four native breeds officially recognized by the Department of Livestock Development, Ministry of Agriculture and Cooperatives, Thailand, namely Kho-Khaolumpoon (Northern Thailand), Kho-Isaan (KI, Northeastern Thailand), Kho-Lan (KL, Central Thailand), and Kho-Chon (Southern Thailand) [2]. They are distinct from each other by phenotypic and genetic traits as well 
as geographical regions of origin [2].

Thai native beef has less fat, greater proportion of polyunsaturated fatty acids, high conjugated linoleic acids and low cholesterol compared to Bos taurus crossbreds thereby making it a favorable option for health-conscious consumers [4]. In addition, it is widely known among local meat processors that Thai native beef offers excellent functionality due to its high water retention capacity in processed traditional Thai meat products such as Look Chin or meatball and Nham or fermented meat. However, Thai native beef is tougher compared to crossbred of Bos taurus [4]. In spite of the established genetic and phenotypic differences among the TNC, the breedinduced variations in meat quality of the TNC remain unclear. In addition, information on muscle fiber types and metabolic properties of different muscles, which underpin the meat quality of TNC is very rare. Elucidating the muscle fiber type of different muscles would yield useful information as to the cuts of TNC meat that could be best suited for particular processing conditions. The functional and biochemical characteristics of each muscle would likely necessitate different processing conditions for optimum utilization of muscles in value-added products [5].

Skeletal muscles consist of different muscle fiber types, varying in biochemical and structural characteristics, which can influence meat quality attributes [6]. Muscle fiber types and the different isoforms of the myosin heavy chain ( $\mathrm{MyHC}$ ) are reliable markers of muscle fiber diversity $[7,8]$. Calpain systems are the major proteolytic enzymes affecting meat tenderness [9]. Currently, there is limited data on the meat quality characteristics, postmortem proteolytic enzymes, and muscle fiber classification of TNC. The TNC used in this study were KI and KL from northeastern region and central region, respectively. The northeastern region and central region are respectively the first and second largest region for beef cattle production in Thailand [1]. The objectives of this study were to access the meat quality characteristics, endogenous proteolytic enzymes, collagen content, and $\mathrm{MyHC}$ isoforms as indicators of muscle fiber type as well as metabolic properties of different muscles of TNC.

\section{MATERIALS AND METHODS}

\section{Animal ethics}

Muscle samples used in this study were obtained from two sources, KL cattle from central region Karnjanaburi province which was part of Government projects, sponsored by the Thailand Research Fund (project code RDG5220024) and KI cattle from northeastern region Ubonratchatani province (project code RDG5220025). All experimental procedures were carried out following the animal welfare standards of the Animal Care and Use Committee of Department of Livestock Development, Ministry of Agriculture and Coop- eratives, Royal Thai Government.

\section{Experimental cattle, slaughtering procedure, and muscle sample collection}

The TNC, KL, and KI, seven entire male cattle per each breed were used in this study. The cattle were extensively grazed on natural forage until they reached the target slaughter weight at approximately $150 \mathrm{~kg}$ and the average age was approximately 2 years. All cattle were kept in lairage with access to water for 12 hours prior to slaughter. Weighting, stunning, bleeding, skinning, evisceration, and washing were completed while the carcasses were hung on achilles on an overhead rail. Dressed carcasses were then weighed before being split longitudinally. Muscle samples from Infraspinatus (IF), Longissimus thoracis (LT), and Supraspinatus (SS) muscles were removed from the left side of each carcass within approximately $1 \mathrm{~h}$ postmortem. The samples were trimmed free of all visible fat, cut into $50 \mathrm{~g}$ pieces, snap frozen in liquid nitrogen and kept at $-80^{\circ} \mathrm{C}$ until subsequent calpain systems, glycogen content, and MyHC expression analysis. Simultaneously, the same muscle samples were removed from the right side of each carcass at approximate $1 \mathrm{~kg}$ weight and transported in the icebox to meat science and technology laboratory, Faculty of Agricultural Technology, King Mongkut's Institute of Technology Ladkrabang, Thailand and kept in a walk-in chiller $\left(2^{\circ} \mathrm{C} \pm 2^{\circ} \mathrm{C}\right)$ for $48 \mathrm{~h}$ postmortem before measuring color and $\mathrm{pH}$. Each muscle sample was cut longitudinally into two $3 \mathrm{~cm}$ thickness sub samples, the sub-samples were vacuum packaged, and stored at $-20^{\circ} \mathrm{C}$ until subsequent shear force, nutrient composition, collagen content, and troponin $\mathrm{T}$ degradation analyses.

\section{Analysis of myosin heavy chain expression}

Muscles of cattle known to express specific MyHC isoforms [8] were used as controls: masseter (MA) (MyHC I only), cutaneus trunci (CT) (MyHC IIa and IIx), diaphragm (DI) (MyHC I and IIa), and trapezius (TZ) (MyHC I, IIa, and IIx). These were obtained from TNC. For each muscle sample, $\mathrm{MyHC}$ isoforms were separated by gel electrophoresis following the method of Picard et al [10].

\section{Casein zymography}

The activities of calpain 1 and calpain 2 were analyzed using casein zymography according to the method described by Arther and Mykles [11]. A $200 \mathrm{mg}$ of the crushed sample was homogenized in $2 \mathrm{~mL}$ of extraction buffer ( $50 \mathrm{mM}$ Tris/ $\mathrm{HCl}$ [pH 7.5], $5 \mathrm{mM}$ ethylenediaminetetraacetic acid (EDTA), $200 \mu \mathrm{g} / \mathrm{mL}$ of 2-[4-aminoethyl]-benezenesulphonyl fluoride, $1 \mu \mathrm{g} / \mathrm{mL}$ of leupeptin, $1 \mu \mathrm{g} / \mathrm{mL}$ of pepstatin). After centrifugation at $15,000 \times \mathrm{g}$ for $20 \mathrm{~min}$ at $4^{\circ} \mathrm{C}$, the supernatant was collected and mixed with 1:1 with sample buffer $(125 \mathrm{mM}$ Tris-HCl pH 6.8, 0.1 M 1,4-dithiothreitol (DTT), 20\% [v/v] 
glycerol, $0.01 \%$ [w/v] bromophenol blue). The mixed supernatant was loaded onto a non denaturing gel consisting of $2 \%(\mathrm{w} / \mathrm{v})$ casein incorporated into $10 \%(\mathrm{w} / \mathrm{v})$ acrylamide separating gel with $5 \%(\mathrm{w} / \mathrm{v})$ stacking gel without casein. The gels were pre-run for $30 \mathrm{~min}$ at $4^{\circ} \mathrm{C}$ in electrophoresis buffer ( $25 \mathrm{mM}$ Tris, $125 \mathrm{mM}$ glycine, $1 \mathrm{mM}$ EDTA, $1 \mathrm{mM}$ DTT, pH 8.3) at 125 V. Samples were loaded at approximately $100 \mu \mathrm{g}$ of protein with equal wet weight of tissue equivalent per well and electrophoresed on gels under pre-run conditions at $125 \mathrm{~V}$ for $4 \mathrm{~h}$ at $4^{\circ} \mathrm{C}$. Thereafter, gels were incubated in buffer containing $50 \mathrm{mM}$ Tris- $\mathrm{HCl}$, pH 7.0, $5 \mathrm{mM} \mathrm{CaCl}_{2}$ and $10 \mathrm{mM}$ DTT with three changes. Then gels were fixed in $10 \%(\mathrm{v} / \mathrm{v})$ acetic acid for $10 \mathrm{~min}$, stained with Coomassie staining solution for $30 \mathrm{~min}$ and destained with $10 \%(\mathrm{v} / \mathrm{v})$ acetic acid. The bands in the gel were quantified using Quantity One Multi Analyst imaging software (Bio-Rad, Hercules, CA, USA).

\section{Calpastatin by iElisa}

Calpastatin was measured by iElisa using anti-calpastatin (in house), before using in house antibody for sample analysis. Prior to that, the in house anti-calpastatin was tested against calpastatin antigen (208902, Millipore Merck, Billerica, MA, USA), which is located in a region found in all calpastatins, and the result was compared with commercial antibody (clone 1F7E3D10, Sigma, St. Louis, MO, USA). The result showed a highly significant correlation between in house antibody and commercial antibody $(\mathrm{r}=0.964, \mathrm{p}<0.01)$.

A portion of the frozen muscle (approximately $10 \mathrm{~g}$ ) was weighed and extracted in 2 volumes of ice-cold extraction buffer (100 mM Tris/HCl; pH 8.0; 10 mM EDTA). Tissue was homogenized for $15 \mathrm{~s}$ using a polytron on high speed. The homogenate was centrifuged at $16,000 \times \mathrm{g}$ for $15 \mathrm{~min}$ at $4^{\circ} \mathrm{C}$. After centrifugation, the supernatant fraction was collected, heated at $95^{\circ} \mathrm{C}$ for $5 \mathrm{~min}$, cooled on ice for $10 \mathrm{~min}$, and then centrifuged at $16,000 \times \mathrm{g}$ for $15 \mathrm{~min}$ at $4^{\circ} \mathrm{C}$. Protein concentrations of the heated supernatant fraction were determined by the method of Lowry et al [12]. The heated muscle homogenates were diluted to $4 \mathrm{mg} / \mathrm{mL}$ in phosphate buffer saline (PBS). The diluted samples $(100 \mu \mathrm{L} /$ well $)$ were incubated in a 96 well plate (Maxisorb; Nunc, Roskilde, Denmark) for $2 \mathrm{~h}$ at $37^{\circ} \mathrm{C}$. Wells were emptied and washed three times with PBS containing 0.05\% Tween-20 (TPBS), blocked with $1 \%$ skim milk in TPBS for $1 \mathrm{~h}$ at $37^{\circ} \mathrm{C}$ and then incubated for $1 \mathrm{~h}$ at $37^{\circ} \mathrm{C}$ with $100 \mathrm{~mL} /$ well rabbit anticalpastatin antibody diluted to $30 \mathrm{mg} / \mathrm{mL}$ immunoglobulin $\mathrm{G}$ (IgG) in $1 \%$ BSA-TPBS. Wells were then washed three times with TPBS and goat anti-rabbit IgG-peroxidase conjugate (1:2,000 dilution; A-6154 Sigma-Aldrich, St. Louis, MO, USA) in $1 \%$ BSA-TPBS was applied for $1 \mathrm{~h}$ at $37^{\circ} \mathrm{C}$. Following three washes with TPBS, $100 \mathrm{~mL} /$ well 3,3',5,5'-tetramethylbenzidine (002023; Invitrogen, Carlsbad, CA, USA) substrate was applied, and this resulted in formation of a soluble blue product. After $15 \mathrm{~min}$ at $37^{\circ} \mathrm{C}$, the reaction was stopped by adding $100 \mathrm{~mL} /$ well of $0.01 \%$ sodium dodecyl sulfate (SDS) to each well and absorbances were measured at $650 \mathrm{~nm}$ in a microplate reader (Infinite F50, Tecan, Männedorf, Switzerland).

\section{Western blot for anti-troponin $\mathrm{T}$}

Muscle tissue submerged in liquid nitrogen was crushed into powder and the western blot anti-troponin $\mathrm{T}$ was assessed as described by Chaosap et al [13]. A $300 \mathrm{mg}$ of crushed sample was homogenized in $6 \mathrm{~mL}$ of extraction buffer $(50 \mathrm{mM}$ Tris/HCl pH 7.5, 5 mM EDTA, with protease inhibitors 200 $\mu \mathrm{g} / \mathrm{mL}$ 2-(4-aminoethyl)- benzenesullphonyl fluoride, $1 \mu \mathrm{g} / \mathrm{mL}$ leupeptin, $1 \mu \mathrm{g} / \mathrm{mL}$ pepstatin for $60 \mathrm{~s}$. Whole homogenate was added to an equal volume of $2 \times$ SDS sample mix (125 $\mathrm{mM}$ Tris-HCl pH 6.8, 4\% [w/v] SDS, $0.1 \mathrm{M}$ DTT, 20\% [v/v] glycerol, $0.01 \%$ [w/v] bromophenol blue). Samples in SDS sample mix were boiled at $100^{\circ} \mathrm{C}$ for $5 \mathrm{~min}$ before loading onto pre cast $10 \%$ stain free gel with $5 \%$ stacking gel. Gels were run on a vertical dual plate unit at $200 \mathrm{mV}$ in $1 \times$ SDS running buffer for approximately $45 \mathrm{~min}$. The separated proteins on gels were transferred to PVDF membranes using a trans blot tank with electrodes (Bio-Rad, USA) filled with transfer buffer (400 mM glycine, $25 \mathrm{mM}$ Tris, $5 \%$ [v/v] isopropanol) at a constant current of $200 \mathrm{~mA}$ for $2 \mathrm{~h}$. Proteins transferred onto membranes were blocked with $5 \%$ milk (w/v) in TBS-T for $1 \mathrm{~h}$ at $25^{\circ} \mathrm{C}$, subsequently probed by anti-troponin $\mathrm{T}$ diluted to $1: 7,500$ in $5 \%(\mathrm{w} / \mathrm{v})$ milk TBS-T overnight at $4^{\circ} \mathrm{C}$ and washed with $1 \%(\mathrm{w} / \mathrm{v})$ milk TBS-T for $6 \times 5 \mathrm{~min}$ with fresh changes of solution. The membrane was then incubated for $1 \mathrm{~h}$ with anti-mouse conjugated with $\operatorname{IgG}$ horseradish peroxidase diluted to $1: 7,500$ in $5 \%(\mathrm{w} / \mathrm{v})$ milk TBS-T and washed with $1 \%(\mathrm{w} / \mathrm{v})$ milk TBS-T as mentioned before. The proteins on membrane were detected with chromogenic substrates. The intensity of visually detectable bands was quantified using a Quantity one Multi Analyst imaging software (Bio-Rad, USA).

\section{Nutrient composition measurements}

The meat samples were analyzed for dry matter (DM), crude protein $(\mathrm{CP})$, ether extract (EE), and ash according to $\mathrm{AOAC}$ [14]. DM was determined at $105^{\circ} \mathrm{C}$ for $12 \mathrm{~h}$ followed by cold weighing. Nitrogen content was determined by the micro Kjeldahl method and was multiplied by 6.25 to determine $\mathrm{CP}$. The EE was determined using petroleum ether in the Soxhlet apparatus. Ash was determined by placing sample in a furnace at $550^{\circ} \mathrm{C}$ for $6 \mathrm{~h}$.

\section{Glycogen analysis}

Muscle glycogen concentrations were determined as described by Dreiling et al [15]. Briefly, $200 \mathrm{mg}$ of muscle sample was 
homogenized with $2 \mathrm{~mL}$ cold $8 \%$ (v/v) perchloric acid using a polytron (Ultra Turrax T25 disperser, IkA-Labortechnik, Staufen, Germany) and then centrifuged at $15,000 \times$ f for 10 $\mathrm{min}$. The supernatant was neutralized with saturated sodium bicarbonate solution and $0.2 \mathrm{M}$ sodium acetate buffer $(\mathrm{pH}$ 4.8). A glycogen standard curve was established by dissolving 0 to $90 \mu \mathrm{g}$ of bovine liver glycogen (Cas no. 9005-79-2, SigmaAldrich, Darmstadt, Germany) in neutralized perchloric acid. Each standard and neutralized supernatant were incubated in amyloglucosidase solution (A7255, Sigma-Aldrich, Germany) for $30 \mathrm{~min}$ at $55^{\circ} \mathrm{C}$ to convert glycogen to glucose. The concentration of glucose was determined using Enzymatic Glucose Reagent (Infinity Glucose Oxidase Reagent, Thermo Scientific, Lidcomb, NSW, Australia), by measuring the absorbance at $550 \mathrm{~nm}$ on a 96-well microplate reader (Infinite F50, Tecan, Switzerland).

\section{Determination of collagen}

The concentration of soluble, insoluble, and total collagen were determined as described by Hill [16]. Briefly, $0.9 \mathrm{~g}$ of the minced meat sample was homogenized with $5 \mathrm{~mL}$ of $1 / 4$ strength Ringer's solution. The homogenate incubated at $77^{\circ} \mathrm{C}$ for $60 \mathrm{~min}$ and then equilibrated at room temperature before centrifuging at 2,500 $\times \mathrm{g}$ for $10 \mathrm{~min}$. The supernatant (soluble collagen) and pellet (insoluble collagen) were separated and hydrolyzed for $24 \mathrm{~h}$ at $110^{\circ} \mathrm{C}$ in $12 \mathrm{~N} \mathrm{HCL}$ and 6 $\mathrm{N} \mathrm{HCl}$, respectively. The cool hydrolysate was added with activated carbon, mixed thoroughly, filtered through Whatman no.1 paper, adjusted $\mathrm{pH}$ to approximately 6.7 , and diluted with distilled water to either 100 or $500 \mathrm{~mL}$ for soluble and insoluble assay, respectively. A hydroxyproline standard curve was prepared by dissolved hydroxyproline standard (56250, Sigma-Aldrich, Germany) in concentrations ranging from 1 to $7 \mathrm{mg} / \mathrm{mL}$. Then, $400 \mu \mathrm{L}$ of each standard or sample diluted hydrolysate was added $200 \mu \mathrm{L}$ of freshly prepared Chloramine T hydrate (Cas no. 149358-73-6, Sigma-Aldrich, Germany) in an aqueous buffer solution ( $\mathrm{pH}$ 6.0) which contained $\mathrm{NaOH}$, citric acid, sodium acetate and 1-propanol and incubated at room temperature for $20 \mathrm{~min}$. Then $200 \mu \mathrm{L}$ of 4-dimethylamino-benzaldehyde reagent (4132845; Ehrlich's reagent, Sigma-Aldrich, Germany) in an aqueous solution containing strong $(70 \%)$ perchloric acid and 2-propanol was added and incubated at $60^{\circ} \mathrm{C}$ for $20 \mathrm{~min}$ then at $25^{\circ} \mathrm{C}$ for $20 \mathrm{~min}$. Absorbance at $550 \mathrm{~nm}$ was measured with a microplate reader (Infinite F50, Tecan, Switzerland). Hydroxyproline content was determined using a standard curve for hydroxyproline with the collagen content being calculated from the hydroxyproline content using a conversion factor of 7.25 .

\section{Meat quality measurements}

The $\mathrm{pH}$ of the IF, LT, and SS muscles was measured at $48 \mathrm{~h}$ postmortem using a $\mathrm{pH}$ meter with a puncture electrode (Model SG2 - ELK Seven Go, Mettler-Toledo International Inc., Giessen, Germany).

The Cielab L* (lightness), $\mathrm{a}^{\star}$ (redness), and $\mathrm{b}^{*}$ (yellowness) values of each muscle sample were measured using a chromameter (CR-300, Konica Minolta, Osaka, Japan) with an illuminant D65 light source. Three measurements were taken from each sample and the average was recorded.

For cooking loss, the samples were weighed, vacuum-sealed using plastic bags and then cooked in a constant $80^{\circ} \mathrm{C}$ water bath for $30 \mathrm{~min}$ or until core temperature of meat sample reached $70^{\circ} \mathrm{C}$. The cooked samples were cooled down to room temperature before weighing. Cooking loss of meat sample was expressed as percent weight loss over the initial weight before cooking. Eight $1 \mathrm{~cm} \times 2 \mathrm{~cm} \times 1 \mathrm{~cm}$ slices were removed parallel to the fiber orientation through the thickest portion of the cooked muscle.

Warner-Bratzler shear force was determined by using a universal testing machine (model 2519-104, Instron, Norwood, Massachusetts, USA) equipped with a Warner-Bratzler shear head operating at a crosshead speed of $50 \mathrm{~mm} / \mathrm{min}$.

\section{Statistical analysis}

Data were analyzed using the general linear model procedure of SAS (SAS Institute Inc., Cary, North Carolina, USA). The model included the effects of cattle breed (B), muscle $(\mathrm{M})$, and $\mathrm{B} \times \mathrm{M}$ interaction and random residual error. Leastsquare means were separated by using the PDIFF option. The Pearson correlation coefficients were tested between $\mathrm{MyHC}$ expression and meat characteristics. The level of significant adopted was $\mathrm{p}<0.05$.

\section{RESULTS}

\section{Myosin heavy chain expression}

The MyHC isoforms in different muscles of KI and KL separated by gel electrophoresis are presented in Figure 1. Breed and muscle type interaction was not significant for the expression of MyHC I and MyHC IIa in TNC (Table 1). The expression of MyHC I was not influenced $(\mathrm{p}=0.051)$ by TNC breed. The IF muscle had higher MyHC I $(\mathrm{p}<0.0001)$ compared with other muscles. The LT muscle had the least $\mathrm{MyHC}$ I. The expression of MyHC IIa was neither different between TNC breeds $(\mathrm{p}=0.519)$ nor among muscle types $(\mathrm{p}$ $=0.285)$. There was a significant interaction $(p=0.038)$ between breed and muscle for MyHC IIx. As shown in Figure 2, MyHC IIx of KI was lower in IF and SS but higher in LT than that of KL.

\section{Calpain systems and degradation product of troponin $\mathrm{T}$}

There was no significant interaction between breed and 


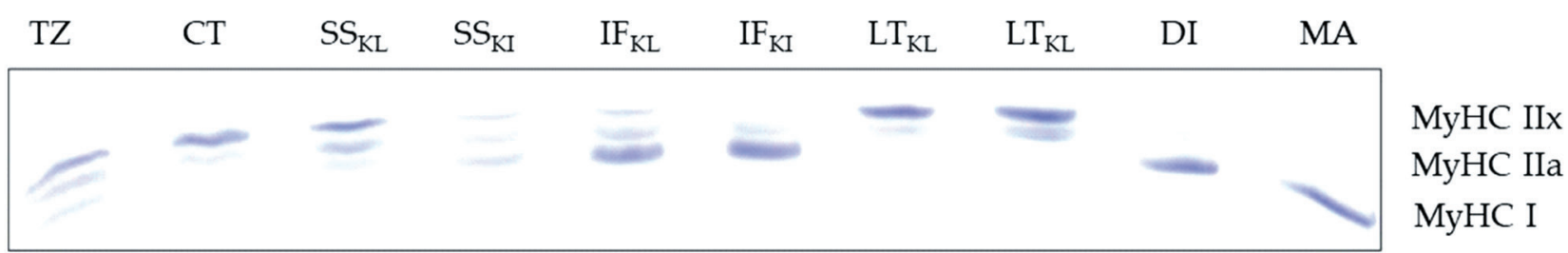

Figure 1. Electrophoresis profile of myosin heavy chain (MyHC) isoforms in infraspinatus (IF), Longissimus thoracic (LT), and supraspinatus (SS) muscles of Kho-Lan (KL) and Kho-Isaan (KI). Trapezius (TZ), cutaneous trunci (CT), diaphragm (DI), and masseter (MA) from Boer crossbred goat were used as controls to classify the isoforms.

Table 1. Myosin heavy chain isoforms relative percentage expression in three muscle types (M) from two breeds (B) of Thai native cattle from central and northeastern parts of Thailand

\begin{tabular}{|c|c|c|c|c|c|c|c|c|c|}
\hline \multirow{2}{*}{ Traits ${ }^{1)}$} & \multicolumn{2}{|c|}{ Breed $^{2)}$} & \multicolumn{3}{|c|}{ Muscle $^{3)}$} & \multirow{2}{*}{ RMSE } & \multicolumn{3}{|c|}{ p-value } \\
\hline & $\mathbf{K L}$ & KI & IF & LT & SS & & B & $M$ & $B \times M$ \\
\hline $\mathrm{MyHC} \mathrm{I}$ & 34.62 & 41.91 & $61.53^{a}$ & $10.57^{\circ}$ & $42.69^{b}$ & 11.69 & 0.051 & $<0.0001$ & 0.340 \\
\hline MyHC Ila & 24.72 & 23.11 & 25.54 & 21.09 & 25.11 & 8.04 & 0.519 & 0.285 & 0.564 \\
\hline MyHC IIx & $40.66^{a}$ & $34.98^{b}$ & $12.93^{c}$ & $68.34^{a}$ & $32.20^{\mathrm{b}}$ & 8.65 & 0.041 & $<0.0001$ & 0.038 \\
\hline
\end{tabular}

RMSE, root mean square error.

1) Arbitrary densitometry units $/ 0.2 \mathrm{~g}$ of wet weight muscle.

2) KL, Kho-Lan (central origin); Kl, Kho-Isaan (northeastern origin).

${ }^{3)}$ IF, Infraspinatus; LT, Longissimus thoracis; SS, Supraspinatus.

${ }^{a-c}$ LS means having different superscripts along the same row within each main effect are significantly different $(p<0.05)$.

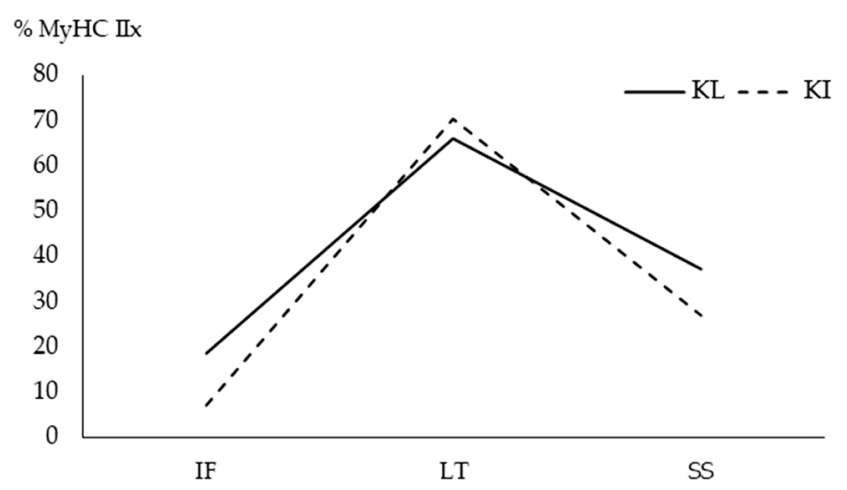

Figure 2. Interaction between Thai native cattle breeds and muscle types on relative percentage (\%) of myosin heavy chain (MyHC) IIx present in infraspinatus (IF), Longissimus thoracic (LT), and supraspinatus (SS) muscles of Kho-Lan (KL) and Kho-Isaan (KI) determined by gel electrophoresis.

muscle type on calpain activity, calpastatin concentration, and degradation product of troponin T in TNC (Table 2). Breed and muscle type did not affect calpain 1 and calpain 2 activity. Calpastatin content in KI was higher $(\mathrm{p}=0.006)$ than that of KL. Calpastatin content did not differ among muscle types. Breed did not affect the relative percentage of the 30 $\mathrm{kDa}$ degradation product of troponin $\mathrm{T}$ on day 2 postmortem. The LT had higher $(\mathrm{p}=0.004)$ troponin $\mathrm{T}$ degradation product than other muscles.

Nutrient compositions and meat quality characteristics There was no significant interaction between breed and mus- cle type for nutrient composition in TNC (Table 3). The KL had lower CP $(\mathrm{p}<0.0001)$ and higher moisture $(\mathrm{p}<0.0001)$ than KI. Breed had no effect on EE and ash in TNC beef.

As might be expected, there were significant differences between muscles for all the parameters assessed $(\mathrm{p}<0.05)$ with the slow type IF (high proportion of MyHC I expression) and fast type LT (high proportion of MyHC IIx expression) being at the extremes (Table 3). The CP of IF and SS was lower $(p<0.0001)$ than that of LT. The EE of IF was lower $(p=0.0002)$ than that of LT. The EE of SS was similar to that of IF. The LT had lower moisture $(\mathrm{p}<0.0001)$ than IF and SS. Ash was higher $(\mathrm{p}<0.0001)$ in LT than in IF and SS.

There was no significant interaction between breed and muscle type on meat quality characteristics in TNC, except for $\mathrm{pH}_{48}(\mathrm{p}=0.023)$ as shown in Figure 3. The $\mathrm{pH}_{48}$ of IF and SS of both KI and KL did not differ ( $p>0.05)$. However, the LT of KI exhibited lower $\mathrm{pH}_{48}$ than did the LT of KL $(\mathrm{p}<0.05)$. Breed had no effect on muscle glycogen $(p=0.066)$, total collagen ( $p=0.534)$, soluble collagen $(p=0.309)$, insoluble collagen ( $p=0.429)$, and $b^{*}(p=0.053)$ in TNC. The LT had higher glycogen $(\mathrm{p}=0.037)$, lower insoluble collagen $(\mathrm{p}=$ $0.002)$, and total collagen $(\mathrm{p}=0.002)$ and tended to have lower soluble collagen $(\mathrm{p}=0.052)$ compared to other muscles. Total collagen and insoluble collagen did not differ between SS and IF. The KL had higher lightness $(\mathrm{p}<0.0001)$ and lower redness ( $\mathrm{p}<0.0001)$, cooking loss $(\mathrm{p}=0.013)$, and shear force $(\mathrm{p}<0.0001)$ than the KI. The IF had lower lightness $(\mathrm{p}<0.0001)$ and higher redness $(\mathrm{p}<0.0001)$ than did other muscles. Lightness did not differ between LT and SS. The LT had lower 
Table 2. Calpain system and Troponin T degradation product in three muscle types (M) from two breeds (B) of Thai native cattle from central and northeastern parts of Thailand

\begin{tabular}{|c|c|c|c|c|c|c|c|c|c|}
\hline \multirow{2}{*}{ Traits } & \multicolumn{2}{|c|}{ Breed $^{1)}$} & \multicolumn{3}{|c|}{ Muscle $^{2)}$} & \multirow{2}{*}{ RMSE } & \multicolumn{3}{|c|}{ p-value } \\
\hline & KL & KI & IF & LT & SS & & B & M & $\mathrm{B} \times \mathrm{M}$ \\
\hline \multicolumn{10}{|l|}{ Calpain activity ${ }^{3)}$} \\
\hline Calpain 2 & 4.58 & 4.56 & 4.61 & 4.53 & 4.57 & 0.56 & 0.922 & 0.936 & 0.689 \\
\hline Calpastatin ${ }^{4)}$ & $0.20^{b}$ & $0.25^{\mathrm{a}}$ & 0.23 & 0.22 & 0.22 & 0.06 & 0.006 & 0.964 & 0.081 \\
\hline
\end{tabular}

RMSE, root mean square error.

1) KL, Kho-Lan (central origin); KI, Kho-Isaan (northeastern origin).

2) IF, Infraspinatus; LT, Longissimus thoracis; SS, Supraspinatus.

${ }^{3)}$ Arbitrary densitometry units (AU)/0.2 g of wet weight muscle.

4) Arbitrary absorbance values of calpastatin/100 $\mu$ g protein.

5) Total intensity of intact and degradation products of Troponin T within each sample is taken as $100 \%$. Values indicated are relative percentage of the signal intensity of degradation product.

a,b LS means having different superscripts along the same row within each main effect are significantly different $(p<0.05)$.

Table 3. Meat characteristics of three muscle types (M) from two breeds (B) of Thai native cattle from central and northeastern parts of Thailand

\begin{tabular}{|c|c|c|c|c|c|c|c|c|c|}
\hline \multirow{2}{*}{ Trait } & \multicolumn{2}{|c|}{ Breed $^{1)}$} & \multicolumn{3}{|c|}{ Muscle $^{2)}$} & \multirow{2}{*}{ RMSE } & \multicolumn{3}{|c|}{ p-value } \\
\hline & $\mathbf{K L}$ & KI & IF & LT & SS & & B & $M$ & $B \times M$ \\
\hline Crude protein (\%) & $19.35^{b}$ & $20.29^{a}$ & $19.16^{\mathrm{b}}$ & $20.62^{a}$ & $19.69^{b}$ & 0.56 & $<0.0001$ & $<0.0001$ & 0.674 \\
\hline Ether extract (\%) & 1.03 & 0.93 & $1.22^{\mathrm{a}}$ & $0.68^{b}$ & $1.03^{\mathrm{a}}$ & 0.30 & 0.316 & 0.0002 & 0.672 \\
\hline Moisture (\%) & $78.31^{a}$ & $77.07^{\mathrm{b}}$ & $78.02^{\mathrm{a}}$ & $77.06^{b}$ & $77.99^{\mathrm{a}}$ & 0.57 & $<0.0001$ & $<0.0001$ & 0.254 \\
\hline Ash (\%) & 1.12 & 1.13 & $1.10^{b}$ & $1.17^{\mathrm{a}}$ & $1.11^{\mathrm{b}}$ & 0.038 & 0.202 & $<0.0001$ & 0.346 \\
\hline Glycogen (mg/g wet weight) & 25.58 & 31.89 & $28.27^{\mathrm{b}}$ & $35.06^{a}$ & $22.88^{b}$ & 11.48 & 0.066 & 0.037 & 0.465 \\
\hline \multicolumn{10}{|l|}{ Collagen (mg/g wet weight) ${ }^{3)}$} \\
\hline SC & 0.55 & 0.49 & 0.53 & 0.42 & 0.61 & 0.19 & 0.309 & 0.052 & 0.599 \\
\hline IC & 5.41 & 5.81 & $5.82^{a}$ & $4.35^{b}$ & $6.66^{a}$ & 1.60 & 0.429 & 0.002 & 0.860 \\
\hline $\mathrm{TC}$ & 5.96 & 6.30 & $6.35^{\mathrm{a}}$ & $4.78^{b}$ & $7.27^{a}$ & 1.73 & 0.534 & 0.002 & 0.924 \\
\hline \multicolumn{10}{|l|}{ Color } \\
\hline$L^{*}$ & $38.20^{\mathrm{a}}$ & $32.72^{b}$ & $33.19^{b}$ & $36.64^{a}$ & $36.55^{\mathrm{a}}$ & 2.94 & $<0.0001$ & 0.005 & 0.814 \\
\hline$a^{*}$ & $12.69^{b}$ & $14.73^{\mathrm{a}}$ & $16.40^{\mathrm{a}}$ & $10.62^{c}$ & $14.11^{b}$ & 1.52 & 0.0001 & $<0.0001$ & 0.094 \\
\hline$b^{\star}$ & 13.57 & 14.32 & $14.83^{\mathrm{a}}$ & $12.64^{b}$ & $14.38^{a}$ & 1.22 & 0.053 & $<0.0001$ & 0.183 \\
\hline $\mathrm{pH}_{48}$ & 5.81 & 5.78 & $6.03^{a}$ & $5.43^{b}$ & $5.93^{\mathrm{ab}}$ & 0.16 & 0.614 & $<0.0001$ & 0.023 \\
\hline Cooking loss (\%) & $41.17^{b}$ & $45.56^{a}$ & 41.68 & 45.09 & 43.32 & 4.76 & 0.013 & 0.208 & 0.343 \\
\hline Shear force $(\mathrm{kg})$ & $7.03^{b}$ & $9.11^{\mathrm{a}}$ & $6.22^{c}$ & $10.08^{a}$ & $7.92^{b}$ & 1.50 & $<0.0001$ & $<0.0001$ & 0.338 \\
\hline
\end{tabular}

RMSE, root mean square error

1) KL, Kho-Lan (central origin); Kl, Kho-Isaan (northeastern origin).

2) IF, Infraspinatus; LT, Longissimus thoracis; SS, Supraspinatus.

3) SC, soluble collagen; IC, insoluble collagen; TC, total collagen.

a,b LS means having different superscripts along the same row within each main effect are significantly different $(p<0.05)$

redness and yellowness $(\mathrm{p}<0.0001)$ compared with other muscles. Shear force was lower in IF and higher in LT ( $\mathrm{p}<$ 0.0001 ) than other muscles.

\section{Relationships between myosin heavy chain isoforms and meat characteristics}

The muscles selected in this study gave a range of $\mathrm{MyHC}$ expression particularly for MyHC I and MyHC IIx, relative to each other, IF was slow type muscle (high proportion of MyHC I expression) and LT being a fast type muscle (high proportion of MyHC IIx expression). Therefore, the relationship between MyHC isoform expression and the meat characteristics of the muscles was examined (Table 4). MyHC I had a positive correlation with insoluble collagen, total collagen, $\mathrm{pH}, \mathrm{a}^{*}, \mathrm{~b}^{*}, \% \mathrm{EE}$, and $\%$ moisture while it had a negative correlation with $\mathrm{L}^{\star}$, shear force, $\%$ protein, and $\%$ ash $(\mathrm{p}<0.01)$. MyHC IIa negatively correlated with calpastatin $(\mathrm{p}<0.01)$. MyHC IIx negatively correlated with insoluble collagen, total collagen, $\mathrm{pH}, \mathrm{a}^{*}, \mathrm{~b}^{*}$, and $\%$ fat and positively correlated with $\mathrm{L}^{*}$, shear force, $\%$ protein, $\%$ ash, and the degradation product 


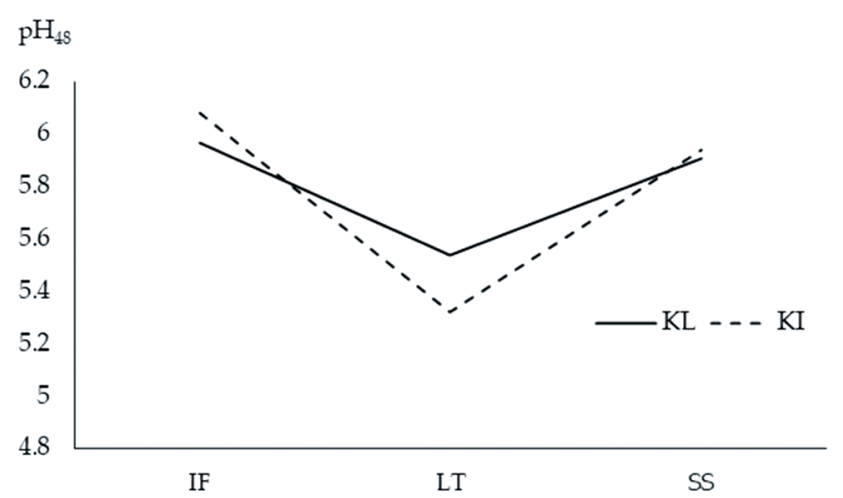

Figure 3. Interaction between Thai native cattle breeds and muscle types on $\mathrm{pH}_{48}$ of infraspinatus (IF), Longissimus thoracic (LT), and supraspinatus (SS) muscles of Kho-Lan (KL) and Kho-Isaan (KI).

of troponin $\mathrm{T}(\mathrm{p}<0.01)$.

\section{DISCUSSION}

Skeletal muscles are composed of different types of muscle fibers, differing in their molecular, structural, contractile, and metabolic properties, which contribute to the differences in their functional capabilities and to the quality of meat $[6,10]$. The expression of MyHC gives an indication of the fiber type of the muscle with high proportions of MyHC I and MyHC IIx being associated with slow and fast type fibers, respectively [6]. The MyHC isoforms were identified with four control TNC muscles; cutaneous trunci (MyHC IIa and MyHC IIx), trapezius (MyHC I, MyHC IIa, and MyHC IIx), Diaphragm (MyHC I and MyHC IIa), and Masseter (MyHC I), whose MyHC isoform composition had been previously confirmed by comparing with ovine, camel, rat, and beef muscles [10].

The muscles of TNC examined in this study contained three MyHC isoforms (I, IIa, and IIx), which was similar to that observed in most large domestic adult mammals $[8,17]$. As expected, there was no detectable MyHC IIb in the muscles considered in the present study, as this isoform is not present in most large animals, except for certain specialized muscles in bovine $[17,18]$. As indicated by the relative percentage expression of $\mathrm{MyHC}$ I, the IF and to some extent the SS, could be considered to be slow type muscles. The LT muscle characterized by high MyHC IIx and low MyHC I could be considered a fast type muscle. The higher expression of MyHC IIx in the KL than in the KI may reflect the differences in growth rate and husbandry conditions. Kim et al [18] observed three MyHC-based fiber types in muscles of Korean native cattle, which was similar to the observation in this study. However, MyHC IIa had the highest expression followed by MyHC IIx in LT [18], which was different from the observation in this study. It seems that the discrepancies in results between studies are caused by the differences in species and breeds. The percentages of slow-MyHC I and fast-MyHC IIa and IIx in LT of TNC examined in this study $(10.57 \%, 21.09 \%$, and $68.34 \%$, respectively) are comparable

Table 4. Relationship between relative percentage of myosin heavy chain isoforms and meat characteristics of Thai native cattle

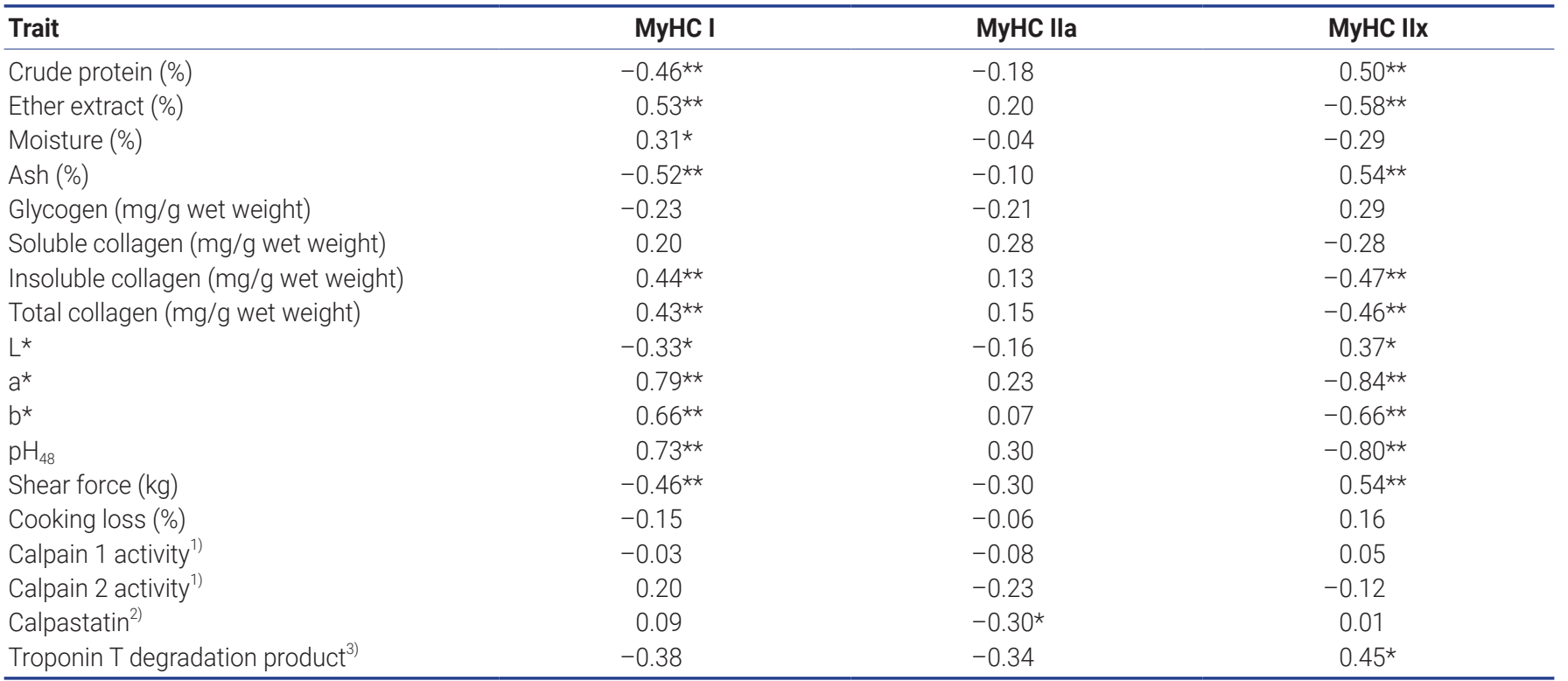

${ }^{\star} p<0.05,{ }^{* \star} p<0.01$.

1) Arbitrary densitometry units $(\mathrm{AU}) / 0.2 \mathrm{~g}$ of wet weight muscle.

2) Arbitrary absorbance values of calpastatin/100 $\mu \mathrm{g}$ protein.

${ }^{3)}$ Total intensity of intact and degradation products of Troponin T within each sample is taken as $100 \%$. Values indicated are relative percentage of the signal intensity of degradation product. 
to the results of Waritthitham et al [19] who found that the LD muscles of Brahman $\times$ TNC had lower percentage of slow twitch fiber than fast twitch fiber $(25.8 \%$ and $74.2 \%$, respectively). Likewise, Kirchofer et al [20] reported that IF muscle containing $\beta$-red fibers greater than $40 \%$ were classified as red while LD muscles containing $\alpha$-white fibers greater than $40 \%$ were classified as white. SS muscle was classified as intermediate due to the similar proportion of all fiber types. The relative differences in MyHC IIx and to a lesser extent MyHC I between KL and KI meat may reflect differences in growth rate and husbandry conditions between the TNC breeds. Similarly, differences in myofiber types were reported in different breeds of cattle [21].

The LT presented higher CP and ash contents, and lower moisture and fat contents than the SS and IF. These observations may be attributed to the differences in the expression of $\mathrm{MyHC}$, reflecting the fiber type of the muscles. Similar to this study, Hwang et al [8] reported higher fat percentage in slow Psoas major than fast Semimembranosus. Conversely, a higher fat percentage was reported in fast LD [9]. The highest glycogen content at slaughter was found in the LT, which was concomitant with the lowest $\mathrm{pH} 48$. This finding agrees with those of previous studies, in which the slow twitch muscles with predominantly type I fibers had lower glycogen concentrations than those with type II or fast twitch muscles [22]. It appears that fast twitch muscles have high glycolytic capacity, which requires glycogen as a substrate. Glycogen concentration varies between the fiber types and this, combined with glycolytic capacity can influence the rate and extent of $\mathrm{pH}$ decline in muscles [23]. Onopiuk et al [24] reported a higher glycogen content in fast-twitch, glycolytic LD muscle $(7.79 \mathrm{mg} / \mathrm{g})$ than that in slow-twitch, oxidative Psoas major $(7.10 \mathrm{mg} / \mathrm{g})$ of beef cattle at $2 \mathrm{~h}$ postmortem. Moreover, the LD muscle had significantly lower $\mathrm{pH}_{48}$ (5.44) than Psoas major (5.53) [24]. The KL meat had lower CP and higher moisture content than did KI. Differences in growth rate and fiber types may be responsible for this observation. Differences in moisture and CP contents have been reported in different cattle breeds [21]. Fat content did not differ between breeds. Similarly, breed did not affect the fat percentage of beef [21]. Contrarily, fat percentage in native breed beef was lower than that of Brahman crossbred and Charolais crossbred beef [4].

Total and insoluble collagen contents were muscle dependent. The IF and SS had higher collagen content than the LT. Likewise, Torrescano et al [25] reported the amounts of collagen in different beef muscles as follows: IF $>\mathrm{LD}>\mathrm{PM}$ while Rhee et al [26] reported a slightly different result: $S S>I F>L D$ $>$ PM. Because of the higher content of MyHC I, IF was the slowest fiber followed by SS while LT was the fastest muscle due to the higher content of MyHC IIx. Thus, it could be inferred that slow IF and SS muscles in beef cattle have higher collagen contents compared with the fast LT muscles. Insoluble and total collagen were positively correlated with MyHC I, and negatively correlated with MyHC IIx in the present study. The relationships between muscle fiber types and meat quality traits such as collagen [25] have been described previously.

The KL meat had higher lightness and lower redness and yellowness than the KI meat. The differences in MyHC IIx and MyHC I content and consequently the fiber type differences between breeds may explain this finding. Our findings are consistent with those of Sethakul et al [4], who reported that LD muscle of grass grazed native Thai cattle had lower lightness, yellowness, and redness values than the Charolais crossbred with heavy slaughter weight in an intensive system. Further, Brahman $\times$ Thai native beef had lower redness and yellowness than the Charolais $\times$ Thai native beef [14] Contrarily, Xie et al [21] observed no differences in the lightness and redness of beef in different cattle breeds. However, differences in meat yellowness were found in different cattle breeds [21]. The LT had higher $\mathrm{L}^{*}$ value and lower $\mathrm{a}^{*}$ and $\mathrm{b}^{*}$ value when compared to other muscles. The lower $\mathrm{b}^{*}$ in LT may reflect its lower intramuscular fat content. The differences in $\mathrm{L}^{\star}$ and $\mathrm{a}^{*}$ may reflect the variation in $\mathrm{MyHC}$ isoforms between the muscles. According to Tortora [27], slow fibers have a high mitochondrial and capillary density and myoglobin content, although they are smaller in size and store less glycogen content than the fast-twitch fibers.

Of all the meat quality measurements, a significant interaction between breed and muscle type was detected for only $\mathrm{pH}_{48}$. The $\mathrm{KI}$ had a larger range in $\mathrm{pH}_{48}$ across muscles than the KL with the fast fiber type muscle LT having the lowest pH48 and the slow fiber type IF having the highest. This relationship was reflected in the correlation analysis where, $\mathrm{pH}_{48}$ was positively correlated with MyHC I and negatively correlated with MyHC IIx. Cooking loss did not differ among the muscles. Contrarily, Rhee et al [26] reported the following cooking losses for different beef muscles: SS (27.3\%)>PM (23.6 \%)>IF, LD (20.7\%). There was significant effect of muscle on shear force measured at $48 \mathrm{~h}$ postmortem with LT having the highest value followed by SS then IF. This observation was unexpected given the lower total and insoluble collagen contents in LT compared with SS and IF. Nonetheless, the lower intramuscular fat may possibly account for the higher shear force in LT. Intramuscular fat in the perimysium could remodel the structure of the intramuscular connective tissue thus lowering the mechanical strength of intramuscular connective tissue and contributing to meat tenderness [28]. Our results contradict the findings of Rhee et al [26], who reported that the shear force values for beef muscles were as follows: SS (4.95 kg)>IF (3.99 kg)>LD (3.27 $\mathrm{kg})$. However, this order does not always hold as Sullivan and Calkins [29] reported a slightly different result: SS (4.71 
$\mathrm{kg})>\mathrm{LD}(4.20 \mathrm{~kg})>\mathrm{IF}(3.2 \mathrm{~kg})$ in Bos taurus and their crossbred indicating that the relative order of shear force values can vary between muscles. The KI meat had higher shear force than the KL meat. This finding may be due to the higher cooking loss, lower moisture content, and higher calpastatin in KI compared with KL. An increase in cooking loss would probably reduce meat tenderness since a certain cross-sectional area of meat would comprise of less water and more structural components [5]. Calpastatin is capable of inhibiting the proteolytic activity of calpain, thereby reducing meat tenderness [13].

Post-mortem proteolysis plays a significant role in the development of meat quality, particularly tenderness. The relative percentage of the $30 \mathrm{kDa}$ degradation product of troponin $\mathrm{T}$ at $48 \mathrm{~h}$ postmortem was significantly different among muscle types, with LT having the highest. This observation agrees with the findings of Christensen et al [30] who reported that postmortem glycolysis occurred faster in fast LD muscle than in slow vastus intermedius (VI) muscle, indicating that the proteolytic potential is greater in LD than in VI muscles. Our findings suggest that the differences in muscle fiber type are expected to have an impact on postmortem proteolysis and tenderization. Although there was a significant effect of muscle on shear force, there was no significant correlation between MyHC expression and the $30 \mathrm{kDa}$ Troponin $\mathrm{T}$ degradation product. This infers that the mechanisms of meat tenderization are multifaceted. Despite the impact of breed on shear force, breed did not influence the $30 \mathrm{kDa}$ degradation product of troponin T. Neither breed nor muscle influenced calpain 1 and calpain 2 activities. Nonetheless, KI muscle had higher calpastatin concentration than the KL muscle at $1 \mathrm{~h}$ postmortem. This observation indicates that there was a higher capacity to inhibit calpain activity in KI than in KL. There has been a consensus that calpain 1, calpain 2 , and calpastatin are largely responsible for postmortem proteolysis in skeletal muscle and meat tenderization [31]. Although calpain 1 plays a major role in postmortem proteolysis [9,31], calpastatin is the specific endogenous inhibitor of calpain. Therefore, high concentrations of calpastatin at slaughter are known to be associated with tougher meat. A previous report has described a negative relationship between calpastatin level in muscle and meat tenderness [32]. A potential reason for higher calpastatin in KI muscles may reflect differences in the balance between protein synthesis and degradation between the species. A typically high muscle calpastatin expression has been shown to be associated with muscle hypertrophy and increased feed utilization efficiency; an extreme example of this is callipyge sheep, which has a very high calpastain expression [33]. Nonetheless, in this study, data on production parameters were not recorded but future work will hopefully assess these parameters.

Overall, the current results indicated that the differences in meat quality due to breed and muscle type of TNC are largely dependent on the distribution of MyHC isoforms. The impact of muscle type on meat quality of TNC was more pronounced than that of breed effect. The KL beef had lower shear force and cooking loss compared to the KI beef. Conversely, the KI beef presented higher redness than the KL beef. The LT muscle had higher shear force than the IF and SS. Thus, these results suggest that processing conditions such as grinding, slicing, and simmering that reduce toughness could be applied to KI meat and the LT muscle of TNC. As such, such meats could be utilized for meat products that require ground beef.

\section{CONCLUSION}

The results of this study revealed that three $\mathrm{MyHC}$ isoforms namely MyHC I, MyHC IIa, and MyHC IIx were detected in IF, LT, and SS in TNC. Breed had no effect on the expression of MyHC I and MyHC IIa. The KL meat had higher MyHC IIx and fat content and lower calpastatin and shear force than the KI. The expression of MyHC I and MyHC IIx was different between muscles reflecting their fiber type with IF and LT, being slow and fast fiber types, respectively. The percentage of MyHC I and IIx were significantly correlated with selected muscle and meat quality traits. The current results indicated clear differences in meat quality between the KL and KI native cattle breeds in Thailand. These results would provide information that could be useful in the processing and utilization of meat from the KL and $\mathrm{KI}$ breeds of native Thai cattle.

\section{CONFLICT OF INTEREST}

We certify that there is no conflict of interest with any financial organization regarding the material discussed in the manuscript.

\section{ACKNOWLEDGMENTS}

This work was supported by a research grant from the Thailand Research Fund (TRF) under grant number RDG5320048. Our special thanks to Prof. Tim Parr and Emeritus Prof. Ronald Bardsley, Division of Nutritional Biochemistry, School of Biosciences, University of Nottingham, for valuable comments and proofreading which greatly improved the manuscript.

\section{REFERENCES}

1. Information and Communication Technology Center. National Animal Statistics. Bangkok, Thailand: Department of Livestock Development; 2018. 
2. Wangkumhang P, Wilantho A, Shaw PJ, et al. Genetic analysis of Thai cattle reveals a Southeast Asian indicine ancestry. Peer J 2015;3:e1318. https://doi.org/10.7717/peerj.1318

3. Kahi AK, Graser HU. Indigenous Thai beef cattle breeding scheme incorporating indirect measures of adaptation: sensitivity to changes in heritabilities of and genetic correlations between adaptation traits. Asian-Australas J Anim Sci 2004; 17:1039-46. https://doi.org/10.5713/ajas.2004.1039

4. Sethakul J, Opatpatanakit Y, Sivapirunthep P, Intrapornudom P. Beef quality under production systems in Thailand: preliminary remarks. In: Proceedings of the 13th, AAAP Animal Science Congress Hanoi; 2008 Sept 22-26: Hanoi, Vietnam.

5. Adeyemi KD, Shittu RM, Sabow AB, et al. Comparison of myofibrillar protein degradation, antioxidant profile, fatty acids, metmyoglobin reducing activity, physicochemical properties and sensory attributes of gluteus medius and infraspinatus muscles in goats. J Anim Sci Technol 2016; 58:23. https://doi.org/10.1186/s40781-016-0105-5

6. Lefaucheur L, Ecolan P, Plantard L, Gueguen N. New insights into muscle fiber types in the pig. J Histochem Cytochem 2002;50:719-30. https://doi.org/10.1177/002215540205000513

7. Choi Y, Kim B-C. Muscle fiber characteristics, myofibrillar protein isoforms, and meat quality. Livest Sci 2009;122:10518. https://doi.org/10.1016/j.livsci.2008.08.015

8. Hwang Y-H, Kim G-D, Jeong J-Y, Hur S-J, Joo S-T. The relationship between muscle fiber characteristics and meat quality traits of highly marbled Hanwoo (Korean native cattle) steers. Meat Sci 2010;86:456-61. https://doi.org/10.1016/j. meatsci.2010.05.034

9. Koohmaraie M, Geesink GH. Contribution of postmortem muscle biochemistry to the delivery of consistent meat quality with particular focus on the calpain system. Meat Sci 2006;74:34-43. https://doi.org/10.1016/j.meatsci.2006. 04.025

10. Picard B, Barboiron C, Chadeyron D, Jurie C. Protocol for high-resolution electrophoresis separation of myosin heavy chain isoforms in bovine skeletal muscle. Electrophoresis 2011;32:1804-6. https://doi.org/10.1002/elps.201100118

11. Arther JSC, Mykles DL. Calpain zymography with casein or fluorescein isothiocyanate casein. In: Elce JS, editor. Calpain methods and protocols. Methods in molecular biology. Humana Press; 2000. pp. 109-16.

12.Lowry OH, Rosebrough NJ, Farr AL, Randall RJ. Protein measurement with the Folin phenol reagent. J Biol Chem 1951;193:265-75.

13. Chaosap C, Sitthigripong R, Sivapirunthep P, Pungsuk A, Adeyemi KD, Sazili AQ. Myosin heavy chain isoforms expression, calpain system and quality characteristics of different muscles in goats. Food Chem 2020;321:126677. https://doi.org/10.1016/j.foodchem.2020.126677

14. AOAC International. Official methods of analysis of AOAC International. 18th ed. Gaithersburg, MD, USA: AOAC
International; 2005.

15.Dreiling CE, Brown DE, Casale L, Kelly L. Muscle glycogen: comparison of iodine binding and enzyme digestion assays and application to meat samples. Meat Sci 1987;20:167-77. https://doi.org/10.1016/0309-1740(87)90009-X

16. Hill $\mathrm{F}$. The solubility of intramuscular collagen in meat animals of various ages. J Food Sci 1966;31:161-6.

17. Picard B, Cassar-Malek I. Evidence for expression of Ilb myosin heavy chain isoform in some skeletal muscles of Blonde d'Aquitaine bulls. Meat Sci 2009;82:30-6. https://doi.org/10. 1016/j.meatsci.2008.11.022

18. Kim GD, Yang HS, Jeong JY. Comparison of characteristics of myosin heavy chain-based fiber and meat quality among four bovine skeletal muscles. Korean J Food Sci Anim 2016; 36:819-28. https://doi.org/10.5851/kosfa.2016.36.6.819

19. Waritthitham A, Lambertz C, Langholz HJ, Wicke M, Gauly M. Muscle fiber characteristics and their relationship to water holding capacity of Longissimus dorsi muscle in Brahman and Charolais crossbred bulls. Asian-Australas J Anim Sci 2010;23:665-71. https://doi.org/10.5713/ajas.2010.90482

20. Kirchofer K, Calkins CR, Gwartney BL. Fiber-type composition of muscles of the beef chuck and round. J Anim Sci 2002;80:2872-8. https://doi.org/10.2527/2002.80112872x

21. Xie X, Meng Q, Cui Z, Ren L. Effect of cattle breed on meat quality, muscle fiber characteristics, lipid oxidation and fatty acids in China. Asian-Australas J Anim Sci 2012;25:824-31. https://doi.org/10.5713/ajas.2011.11462

22. Choe JH, Choi YM, Lee SH, et al. The relation between glycogen, lactate content and muscle fiber type composition, and their influence on postmortem glycolytic rate and pork quality. Meat Sci 2008;80:355-62. https://doi.org/10.1016/j. meatsci.2007.12.019

23. Ferguson DM, Gerrard DE. Regulation of post-mortem glycolysis in ruminant muscle. Anim Prod Sci 2014;54:46481. https://doi.org/10.1071/AN13088

24. Onopiuk A, Półtorak A, Wierzbicka A. Influence of postmortem muscle glycogen content on the quality of beef during aging. J Vet Res 2016;60:301-7. https://doi.org/10.1515/jvetres2016-0046

25. Torrescano G, Sanchez-Escalante A, Gimenez B, Roncales P, Beltrán JA. Shear values of raw samples of 14 bovine muscles and their relation to muscle collagen characteristics. Meat Sci 2003;64:85-91. https://doi.org/10.1016/S0309-1740(02) 00165-1

26. Rhee MS, Wheeler T, Shackelford S, Koohmaraie M. Variation in palatability and biochemical traits within and among eleven beef muscles. J Anim Sci 2004;82:534-50. https://doi. org/10.2527/2004.822534x

27. Tortora GJ. Principles of human anatomy. 10th ed. Hoboken, NJ, USA: John Wiley \& Sons, Inc; 2005.

28. Nishimura T. The role of intramuscular connective tissue in meat texture. Anim Sci J 2010;81:21-7. https://doi.org/10. 
1111/j.1740-0929.2009.00696.x

29. Sullivan G, Calkins C. Ranking beef muscles for WarnerBratzler shear force and trained sensory panel ratings from published literature. J Food Qual 2011;34:195-203. https:// doi.org/10.1111/j.1745-4557.2011.00386.x

30. Christensen M, Henckel P, Purslow PP. Effect of muscle type on the rate of post-mortem proteolysis in pigs. Meat Sci 2004;66:595-601. https://doi.org/10.1016/S0309-1740 (03)00175-x

31. Koohmaraie M, Whipple G, Kretchmar DH, Crouse JD, Mersmann HJ. Postmortem proteolysis in longissimus muscle from beef, lamb and pork carcasses. J Anim Sci 1991;69: 617-24. https://doi.org/10.2527/1991.692617x

32. Whipple G, Koohmaraie M, Dikeman ME, Crouse JD, Hunt MC, Klemm RD. Evaluation of attributes that affect longissimus muscle tenderness in Bos taurus and Bos indicus cattle. J Anim Sci 1990;68:2716-28. https://doi.org/10.2527/ 1990.6892716x

33. Geesink GH, Koohmaraie M. Postmortem proteolysis and calpain/calpastatin activity in callipyge and normal lamb biceps femoris during extended postmortem storage. J Anim Sci 1999;77:1490-501. https://doi.org/10.2527/1999.7761490x 